\title{
Late relapse in IgD myeloma: Value of immunohistochemistry in trephine biopsy
} specimens

Haematology

Department, Belfast

City Hospital, Lisburn

Road, Belfast,

Northern Ireland

BT9 7AB

$P$ Kettle

T C M Morris

Correspondence to:

Dr T C M Morris

Accepted for publication

9 February 1994

\author{
P Kettle, T C M Morris
}

specimen proved invaluable in documenting early relapse. It is suggested that immunohistochemistry should be adopted more widely in view of the disparities evident in aspirates and trephines.

( Clin Pathol 1994;47:773-774)

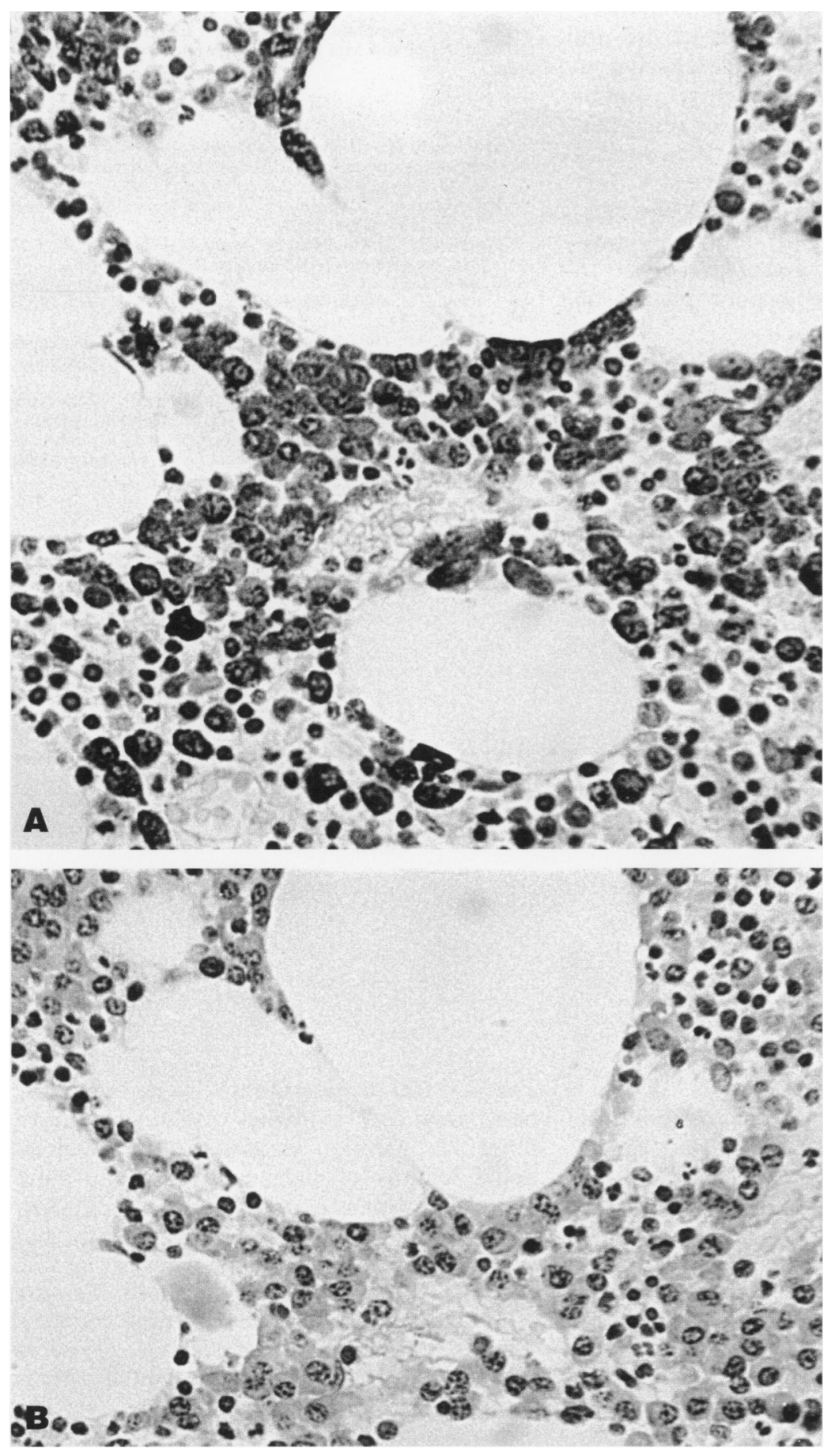

\section{Case report}

In 1980 a 46 year old white man presented with weight loss and back pain. $\operatorname{IgD} \lambda$ myeloma was diagnosed, on the basis of a serum IgD paraprotein of $8 \mathrm{~g} / \mathrm{l}$, extensive lytic lesions on skeletal radiography, an infiltrate of $80 \%$ plasma cells in the bone marrow aspirate, a heavy infiltration of plasma cells in the bone marrow trephine biopsy specimen and normal renal function.

He was treated initially with local radiotherapy and then had 18 courses of VMCP (vincristine $1 \mathrm{mg}$ intravenously on day 1 , melphalan $5 \mathrm{mg} / \mathrm{m}^{2}$ orally for four days, cyclophosphamide $100 \mathrm{mg} / \mathrm{m}^{2}$ orally for four days and prednisolone $60 \mathrm{mg} / \mathrm{m}^{2}$ orally for four days) over a two year period. The paraprotein became undetectable within a month of starting chemotherapy and a bone marrow aspirate at six months showed less than $1 \%$ plasma cells. He remained well with no evidence of paraproteinaemia for over 10 years and no change was noted in the skeletal survey. In 1992 he developed further back pain. Radiographs showed collapse of a previously noted lytic lesion in a lumbar vertebra. No paraprotein was detectable in serum or urine and blood counts were normal. A bone marrow aspirate showed $3 \%$ plasma cells.

The trephine biopsy specimen was processed using standard techniques. The haematoxylin and eosin stained trephine section was not diagnostic of myeloma. Consecutive sections of the trephine were stained using antisera to $\operatorname{IgD}, \lambda$, and $\kappa$ using the indirect immunoperoxidase system. Five hundred cells were counted in each section. The percentage of positive cells in the antiIgD section was $13 \%$, in the anti- $\kappa$ section $1 \%$ and in the anti- $\lambda$ section $15.5 \%$. The figure shows sections stained with (A) anti- $\lambda$ and (B) anti-k. The trephine showed a much greater infiltration than the aspirate, but with the plasma cells occurring in clumps; the $\lambda: \kappa$ ratio of $15 \cdot 5: 1$ proved that the plasma cells were monoclonal.

Relapse was diagnosed and further radiotherapy given. The patient subsequently developed a serum paraprotein $\operatorname{IgD} \lambda$ of $1 \mathrm{~g} / 1$ and $\lambda$ 
chains in his urine $0.2 \mathrm{~g} / 24$ hours. Further chemotherapy was given and his peripheral blood stem cells were harvested with a view to autologous transplantation. As his paraprotein and Bence-Jones protein have since both disappeared with the VMCP regimen, high dose treatment has not been given.

\section{Discussion}

Median survival in myeloma is 36 months, ${ }^{1}$ and although about $2 \%$ of patients survive longer than 10 years, most of these long survivors never had advanced disease. ${ }^{2}$ IgD myeloma is rare, accounting for $1-2 \%$ of cases. ${ }^{3}$ It was first described in $1965^{4}$; the median survival is 13.7 months. ${ }^{3}$ It occurs in a younger age group than other types of myeloma and it has a male predominance. ${ }^{3}$ Our patient was unusual in that he did not have features typical of IgD myeloma, such as hepatomegaly, lymphadenopathy, extraosseous lesions, hypercalcaemia or renal failure. He also did not have Bence-Jones proteinuria, which is almost universal in IgD myeloma, until after his relapse. His prolonged survival after rapidly entering remission is also unusual as a rapid response to treatment is said to be a poor prognostic sign. ${ }^{5}$

The diagnostic criteria for myeloma usually include an assessment of numbers of plasma cells in the bone marrow aspirate. ${ }^{1}$ However, in $48 \%$ of cases the aspirate will underestimate the degree of plasma cell infiltration. ${ }^{6}$
The disparity between the number of plasma cells in the aspirate and the trephine may reflect clumping of plasma cells. This disparity is worrying in view of the reliance many myeloma trials place on the number of plasma cells in the aspirate for diagnosis and trial entry. The simplicity of the immunohistochemical method and its value in this case suggest that it should be adopted more widely.

Finally, the prolonged survival of this patient emphasises that IgD myeloma need not always have a poor prognosis and argues well for more aggressive forms of treatment, currently under trial. The attainment of remission using a relatively non-aggressive protocol, as in this case, may prolong survival.

We thank Dr Geraldine Markey for her helpful comments on the manuscript and Mrs Jackie Creighton for secretarial assistance.

1 McLennan IC, Chapman C, Dunn J, Kelly K. Combined chemotherapy with ABCM versus melphalan for treatment of myelomatosis. Lancet 1992;339:200-5.

2 Kyle RA. Long term survival in multiple myeloma. $N$ Engl f Med 1983;308:314-16.

3 Jancelewicz Z, Takatsuki K, Sugai S, Pruganski W. IgD multiple myeloma. Arch Int Med 1975;135:87-93.

4 Rowe DS, Fahey JL. A new class of human immunoglobulins; I: a unique myeloma protein. $\mathcal{f}$ Exp Med 1965; 121:171-84

5 Hansen OP, Hessen B, Videback A. Prognosis of myelomatosis on treatment with prednisone and cytostatics. Scand $\mathcal{F}$ Haematol 1973;10:282-90.

6 Terpstra WE, Lokhorst HM, Blomjous F, Meuwissen OJA Th, Dekker AW. Comparison of plasma cell infiltration in bone marrow biopsies and aspirates in tration in bone marrow biopsies and aspirates in 82:46-9.
Department of Neuropathology, Institute of

Neurological Sciences, Southern General Hospital, Glasgow G51 4TF

$M$ Tatke

D Doyle

Correspondence to: Dr David Doyle

Accepted for publication 9 February 1994

\begin{abstract}
Teased fibre preparations are important in the investigation of peripheral nerve disorders, but can be a rather tedious procedure. A technique is described in which pretreatment of the nerve sample with collagenase before osmication substantially simplifies the actual teasing procedure. The technique also does not alter the morphology or interfere with any further investigations required on teased fibres-for example, fluorescent antibody studies.
\end{abstract}

(F Clin Pathol 1994;47:774-775)
Teasing of nerve fibres is perhaps the best way of studying individual nerve fibres. It permits measurements of internodal lengths of myelin sheaths and fibre diameter, which can be used to differentiate between segmental demyelination and axonal degeneration. Irregularities in the myelin sheath can also be visualised. Teasing of individual fibres can be very time consuming and considerable practice is required to separate long lengths of individual fibres without causing damage. These aspects prompted us to determine whether pretreatment with collagenase would make the procedure easier. 